\title{
The Effect of Taboo Content on Incidental Vocabulary Acquisition in a Foreign Language: A Facial Expression Analysis Study
}

\author{
Emrah Dolgunsöz \\ Bayburt University, Turkey
}

\begin{abstract}
This study aims to examine how taboo content affects language learner psychology and language learning gains in a multi-modal learning environment by using facial expression analysis. 40 Muslim language learners were initially asked about their opinions on pork and watched a subtitled cooking video including pork visuals and their facial expressions were recorded. Before watching the video, only 20 of them were told it was lamb. The video was followed by a stimulated recall procedure, a cloze test and an output test. The results of the facial data analysis showed that Muslim learners were disgusted by the taboo content, which was in line with their opinions on pork taboo. However, this negative emotion did not significantly affect their test performance. Computer assisted facial expression analysis was also introduced as a biometric research technique for second language research.
\end{abstract}

Key words: EFL, FACET, facial expression analysis, taboo

\section{Introduction}

Our behaviors and perception are not solely moderated by reasoning and rational thinking; the societal and cultural norms have an influential role in governing our actions and our understanding of the world around us. These norms may be culture specific and vary from culture to culture, thus creating the term "taboo". According to the Encyclopedia Britannica (2012), taboo is "the prohibition of an action based on the belief that such behavior is either too sacred and consecrated or too dangerous and accursed for ordinary individuals to undertake." Hence, an ordinary action or content for one society may be restricted to another culture: Muslims and Jewish people do not con-

Correspondence concerning this article should be addressed to Emrah Dolgunsöz, Department of ELT, Faculty of Education, Bayburt University, Turkey. E-mail: edolgunsoz@gmail.com

Received May 17, 2018 sume pork and Hindus never eat beef due to religious restrictions.

For language learners, gaining only systematic knowledge of the target language can never be enough; they are also required to acquire the target schematic knowledge and be familiar with the target culture (Alptekin, 1993). However, embedding cultural topics in language learning materials requires intensive scrutiny; most language teaching materials are designed with utmost care by considering taboo topics in order not to psychologically offend learners from different cultures. One of these taboo topics is "pork" which is a sensitive content for Muslim and Jewish learners of English (Gray, 2002). ELT (English Language Teaching) instructors with Muslim and Jewish audience or publishers pursuing global acceptance avoid the inclusion of this taboo topic such as pig related figures, visuals or even words (i.e., sausage, pork, boar, sow) in their course materials and instructional content; thus diverting learners to learn them from out-of-class contexts. This approach has some merits: a concept, an image or a visual (e.g., a pig figure) that appears natu- 
ral to a European learner may be considered offensive by learners from certain cultures. Taboo offense was also investigated in some related research (Argungu, 1996; Khuwaileh, 2000; Timina \& Butler, 2011) concluding that using taboo motives might pose a negative effect on learner and learner psychology.

Beside its merits, this censorship also seems controversial. An opposing argument is that taboo free ELT content only reflects a romanticized Western culture by focusing on only general themes such as family, festivals or travel (Banegas, 2011), presenting a fake and sanitized culture. The primary but strongest argument has its basis in religious beliefs; pig related visuals and words are censored since they are offensive and have a negative effect on Muslim or Jewish learners. However, the words "offensive" and "negative effect" are not clear enough; how "pork" as a taboo threatens language instruction or learner psychology and academic performance is still vague. Does it hinder learning processes or is it solely a topic, which learners personally avoid? Or, how do offended learners react emotionally when they are exposed to pork content during instruction and how does it affect memory performance?

By using facial expression analysis technique (Ekman, 1982; Essa \& Pentland, 1997), this study primarily aimed to reveal moment-by-moment reactions of Muslim learners towards pork visuals in a multi modal learning environment by objectively recording their facial expressions while they processed pork content for learning purposes. The secondary aim of this research was to see whether pork visuals affected vocabulary learning gains or not.

\section{Facial Expression Analysis Technique and Emotions}

Our face is a complex signal system and facial expressions are the external representations of internal emotional states formed by muscle movements under our skin (Ekman, 1982; Kling \& Brothers, 1992; LeDoux, 1993). Facial muscles create facial expressions, which temporarily change the facial profile. These changes are mostly brief and temporary; rarely lasting over 5 seconds or less than 250 milliseconds (Fasel \& Luettin, 2003). These facial changes have long been considered to be linked to emotions (Buck, 1984; Fridlund, Ekman, \& Oster, 1987) and facial expression analysis refers to the measurement and recognition of these facial expressions regarding specific emotions.

Human emotions are wide but finite. Basically 6 expressions of emotions were defined; joy, anger, disgust, fear, sadness and surprise (Ekman \& Friesen, 1971). Apart from 6 emotions, there are 3 types of emotional valence, which refer to the direction of emotions as positive, neutral and negative (Smith \& Kosslyn, 2013). Valence is an umbrella term covering a wide range of emotions in similar qualities (i.e., anger, sadness and fear are categorized under negative valence).

Analysis of facial expressions dates back to $19^{\text {th }}$ century, albeit, in modern meaning, the most influential work in this area is considered that of Ekman and Friesen (1978), who proposed the Facial Action Coding System (FACS), the most widely used system for facial expression analysis today. FACS defined 44 pre-determined facial spots on the face, each referring to one or more facial muscles called 'Action Units' (AUs). FACS relies on the combinations of these AUs, which refer to a large set of possible facial expressions.

The development of computer based facial expression analysis based on FACS led the practical analysis of facial expressions; thus, recently this technique is on the rise. Its application is totally non-invasive and does not have specific requirements from the participants. Also, in a well implemented experiment, participants are not aware of having their facial expression tracked. Recent computer based facial expres- 
sion analysis can provide process oriented data collection by performing real-time frame-byframe analysis of facial expressions and outputs data for at least 6 emotions and three emotional valences (also see Picard, 1995 for the term "affective computing"). Various fields of research have started to adopt facial expression analysis such as psychology (Calvo, Gutiérrez-García, \& Del Líbano, 2016; Neubauer, Woolley, Khooshabeh, \& Scherer, 2016), artificial intelligence (D’Mello, 2015; Nazari, Lucas, \& Gratch, 2015), food science (Danner, Sidorkina, Joechl, \& Duerrschmid, 2014; Pellegrino, Crandall, \& Seo, 2015;), market research (Neto \& Filipe, 2016) and education (Flynn, 2014; GhasemAghaei, Arya, \& Biddle, 2016). However, facial expression analysis in educational research is yet in its infancy and no studies exist on language learning and teaching context.

\section{Previous Taboo Research in Language Learning and Teaching}

In a critical perspective, taboo research in language pedagogy is contradictory, and says little about the link between taboos and learning performance. Additionally, solely aiming to reveal personal opinions of the learners, most related research is methodologically too subjective. Deckert (1996) examined the writing topic preferences of ESL learners with 105 Asian students enrolled in ESL writing courses at Michigan University. The students were asked to rate 20 topics and choose 10 . The topics included both common subjects such as pollution, advertisements and health and taboo topics such as abortion, pre-marital relationships and bisexuality. According to the results, participants avoided writing about the taboo topics and were
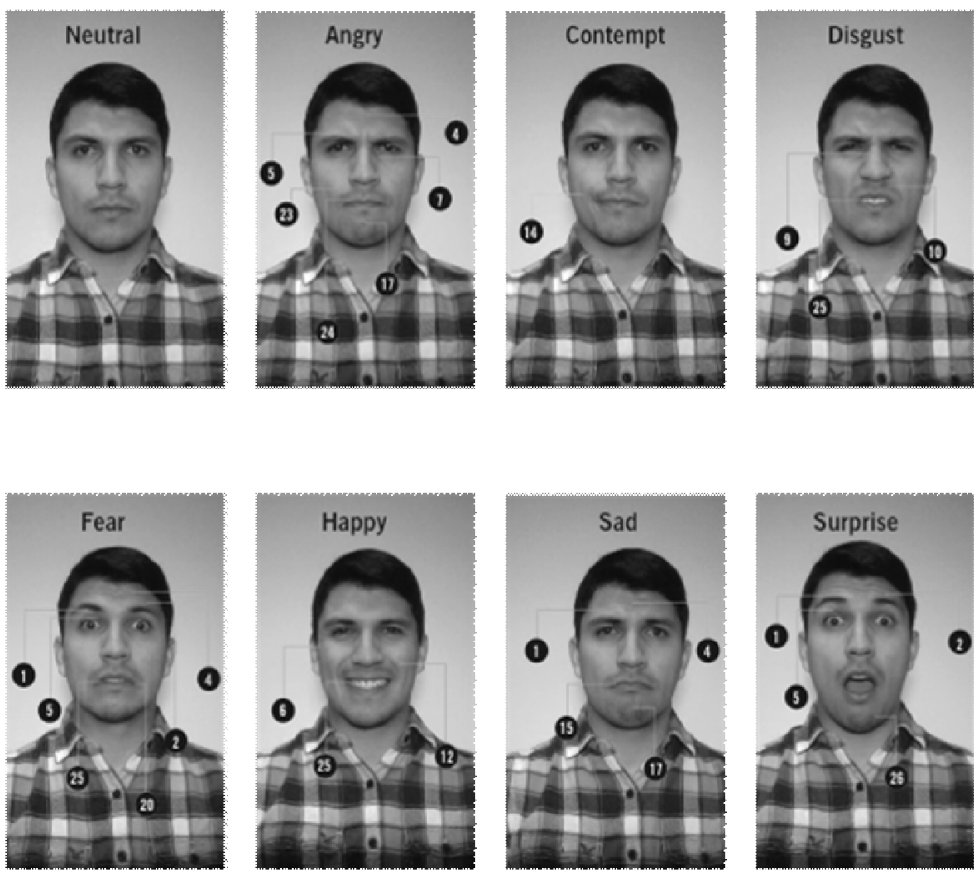

Action Unit (AU) Descriptions

1 Inner Brow Raise

2 Outer Brow Raise

4 Brow Lower

5 Upper Lid Raise

6 Cheek Raise

7 Lid Tighten

9 Nose Wrinkle 10 Upper Lip Raise 12 Lip Corner Pull

14 Dimple 15 Lip Corner Depress 17 Chin Raise 20 Lip Stretch 23 Lip Tighten 24 Lip Press 25 Lips Part 26 Jaw Drop

Figure 1 Some AUs, a neutral face and seven emotions (Taken from iMotions FACETTM FAQ) 
mostly attracted by common subjects. Khuwaileh (2000) evaluated Jordanian EFL learners' perceptions towards sexually sensitive topics such as AIDS and birth control. Data was collected through a questionnaire, structured interview and classroom observations. The results showed that taboo topics caused learners to feel embarrassed and female learners in particular were fairly reluctant to discuss them. The author concluded that such topics should be avoided to maintain efficient learning. Hudson (2011) examined EFL learners' perceptions towards non-Islamic topics in Saudi Arabia. According to the questionnaire results, $60 \%$ of the participants were against using pork as a topic, along with sex, Christian values and alcohol. However, some participants also made positive comments, such as 'The fact that it is taboo and we should not eat it certainly does not mean that we cannot learn about it' (p. 133). In another study by Timina and Butler (2011), 70 Taiwanese students were asked to pick out topics uncomfortable for them, such as sex, politics, homosexuality and personal religious beliefs. The results of interviews and a questionnaire were inconclusive; 39\% learners thought taboo topics should be avoided, while $34 \%$ were indecisive. Only $27 \%$ were positive about taboo topics. Learners also stated that such topics might be embarrassing, as they were not generally discussed in their native culture.

Not all previous taboo-related research showed negative results. Nelson (1999) aimed to create a gay-friendly classroom atmosphere and collected observational data from three ESL classes as they discussed sexual identity and homosexuality. This study also involved verbal data collection instruments such as written work, worksheets and interviews. The results showed that learners were not biased; they participated in discussions and showed an unexpected enthusiasm about the topics. In a more recent study, Tekin (2011) investigated Turkish EFL learners' attitudes towards instructional materials, including homosexuality and pre-marital sex. Pre- and post-questionnaires were used to collect data. Learners discussed these topics in the classroom and were asked how disturbing they found doing so. The learners were found to be enjoying the discussion and not being negative towards the materials. The author added that such topics acted as a catalyzer of motivation. Similarly, in Turkey, Üstünel and Öztürk (2014) evaluated 56 young EFL learners' attitudes, motivation and awareness of target language in a two-week culturally enriched class. They used an attitude and motivation questionnaire, interviews and took field notes to collect data. The learners were highly motivated with foreign culture themes.

Rather than relying solely on subjective data, this study adopted a process oriented biometric approach to reveal learners' emotional reactions while they processed pork content in a multi-modal learning environment and also aimed to reveal any possible effect of pork content on learning gains. Additionally, facial expression analysis as a biometric interdisciplinary technique was introduced for language learning and teaching research. Answers for the following research questions were sought:

1. What are the attitudes of Muslim learners towards pork?

2. How did Muslim EFL learners react to pork content in multi modal learning environment?

a. Were their facial expressions in line with their attitudes towards pork content?

3. Did pork content affect vocabulary learning gains?

\section{Method}

\section{Design}

This study had a between-subject design with two conditions: A "Pork" and a "Lamb meat" condition, in which a group of learners watched pork content (experimental group) and another 
group watched lamb content (control group). Control group and experimental group actually watched the same video including pork but the control group was told that they will watch a recipe video involving lamb meat.

\section{Participants}

40 learners of EFL (English as a foreign language) (20 males and 20 females) from a university in Turkey in an age range of 19 to 23 voluntarily participated in this study and received course credit for their participation. All participants also filled out and signed a consent form in which a general information was given about the study. To control for any effect of language proficiency, participants were randomly chosen among volunteers, who completed English courses during the previous semester over an average of 80 points out of 100 . All participants had the same L1 background and were brought up as Muslims without any international experience. None of the participants were vegetarian. The 40 participants were divided into two groups as the 'Pork Group' (PG) and the 'Lamb Group' (LG) and were randomly assigned to one of these groups. Both groups equally comprised 20 learners (10 males and 10 females). All participants had normal or corrected to normal eyesight and were naive to the research questions.

\section{Apparatus}

To collect facial expression data, FACET ${ }^{\mathrm{TM}}$ software by iMotions ${ }^{\mathrm{TM}}$ with an HD 720p Logitech $^{\mathrm{TM}}$ webcam was used. This biometric platform automatically detects face in front of the computer with a high-quality HD webcam and acquires facial responses through a dedicated algorithm depending on the Facial Action Coding System (FACS) with 19 AUs. The software can register up to 30 frames per second for 7 emotions and 3 valences. In addition to basic 6 emotions, this software is able to analyze one extra emotion: contempt.

\section{Instruments}

\section{Pork Taboo Survey}

To determine participants' attitudes towards pork meat and ensure their unfamiliarity with pork, a 5-question survey was designed to investigate whether the participants had ever seen a pig or pork in real life, whether they had ever eaten pork meat or had any plan to eat it. Learners were also asked to state why they did not choose to eat pork. In the final question, learners were asked to match "pork" with an emotional expression (joy, sadness, surprise, disgust, anger, contempt and fear) or select "no emotion" option.

\section{Disgust Scale}

Disgust scale was a simple verbal data collection instrument in which learners were required to rate the dish from 1 to 10 after watching the recipe video. In this scale, 1 means 'extremely disgusting', 5 refers to 'neutral' and 10 is 'extremely delicious'. This instrument also included a question asking whether the participant would like to eat the meal or not.

\section{Visual Stimulus}

The visual stimulus used was a 3.20-minute cooking video with $1280 \times 720$ resolution, which described step by step how to cook "pork carnitas" - a special dish in Mexican cuisine. The original video was downloaded from the YouTube channel 'Food Wishes', shortened and edited by the researcher to add subtitles. 12 subtitle areas were produced and they were kept simple, comprising short and simple imperatives such as 'put, cut and add' and were 3-6 words in length. The final word for each 
Table 1 Non-words and semantic equivalents

\begin{tabular}{ll}
\hline Non-Words & Semantic Equivalents \\
\hline 1. Baigs & Folio \\
2. Crigg & Knife \\
3. Drinn & Chopping board \\
4. Goomb & Bowl \\
5. Loast & Spice \\
6. Rhird & Tray \\
7. Smang & Spoon \\
8. Thoon & Oven \\
9. Toide & Strainer \\
10. Zirgs & Fat \\
11. Frupe & Water \\
12. Plood & Fork \\
\hline
\end{tabular}

subtitle was substituted with a five letter nonword generated from the ARC Non-Word Database (Rastle, Harrington, \& Coltheart, 2002). Each subtitle lasted about 10 seconds. A sample substitution is shown below:

Cut the meat with a knife $\rightarrow$ Cut the meat with a crigg

\section{Unannounced Post Test}

The unannounced post-test consisted of 36 items and three main sections. Each item was scored as one point. In the first section comprising 12 questions, the same subtitles were given in the same order, leaving the non-word areas blank. Learners were asked to choose the correct non-words among the 18 items ( 6 extra non-words were given as distractors) and fill in the blanks. In this section, the Stimulated Recall Technique (STR) was used to promote retention: the researcher helped the learners by showing the video again, but with the non-words substituted with blanks. This section had a maximum duration of 5 minutes.
For the second section, similar to the first one, 18 non-words were given again, asking learners to place the correct non-words in the given 12 sentences. Unlike in the first section, the sentences did not match the subtitles: they were totally genuine and constructed by the researcher. The sentence structure was kept simple and high-frequency words were used to control any possible interference of EFL proficiency. For the 12 items, learners were given 5 minutes.

The final section was output-oriented; herein, the participants were shown pictures and were required to write down the correct non-words. This time, no clue or set of words were given. The duration of this section was also 5 minutes.

\section{Procedure}

For a preliminary study aiming to reveal learner attitudes towards pork, participants were given the Pork Taboo Survey one week before the experiment. The survey was conducted in- 
dividually under the researcher's control, and participants were free to ask questions about the items. Preliminary findings were important for revealing any correlation between learner subjective pork perception and their real life reactions.

After a week, participants were given a schedule and sat for the experiment individually in a separate room. For facial expression data collection, all participants were baselined. Baselining is a type of calibration process for accurate facial data acquisition, wherein the software shows a grey screen for 6 seconds before the video and the participants' neutral facial profile is registered.

Before watching the video, the PG was told that they would watch, with English subtitles, a cooking video involving pork. After watching the video, they immediately took the disgust scale together with the unannounced post-test. For the LG, participants were tricked and instructed that they would watch a cooking video describing a dish involving lamb meat, with English subtitles. The same procedures were followed for this group. Although both groups watched the same video with the same English subtitles, LG perceived pork as lamb meat.

\section{Data Analysis}

Facial expressions were analyzed by iMotions FACET $^{\mathrm{TM}}$ which works with FACS principles. It registers a facial frame every 32 milliseconds and ascribes a value to each frame regarding 7 basic emotions and 3 valences. This value is termed as "evidence number" ranging between -4 and +4 . A positive evidence score means a stronger probability for an emotion to be expressed while negative values indicate lower probability. For instance, an evidence number of +4 for joy means that participant showed extreme joy towards a stimulus (i.e., laughter). Evidence number of -4 refers to no observable joy expression on the face of the participant. It should be noted that these values are the limits and are considered as extreme (see FACET Manual for details).

Facial data needs to be post processed for reliable results. Before analyzing facial expressions, all data frames were first post-processed by iMotions FACET ${ }^{\mathrm{TM}}$ with a minimum face size of $20 \%$ and two engines. After post processing, $90 \%$ data quality was obtained. The replays were watched by the researcher, and the remaining corrupted parts of the data (mostly caused by sudden head movements) were excluded by placing marker data. After post-processing, baselined raw data was exported for each participant to extract and analyze evidence scores for the 7 emotions and three valences.

After the extraction, the data were analyzed via $t$-tests to reveal group differences and effect of pork content on facial reactions. Descriptive statistics were also employed. To investigate the relationship between disgust scale and disgust evidence, Pearson correlation was used.

Pork Taboo Survey results were given through percentages. For post test results, $t$-tests were adopted to find out vocabulary learning gain differences between groups.

\section{Results}

\section{Preliminary Findings: Learner Attitude to- wards Pork}

The aim of this part was to introduce the results of the Pork Taboo Survey, which was conducted as preliminary research prior to the experimental phase. Survey results were important since they provided valuable insights about subjective pork perception of the participants. The results confirmed the expectations; $70 \%$ of the participants never saw a pig in real life. The remaining $30 \%$ had seen one at the zoo or in mountain villages; however, they probably saw wild boars. None of the learners had ever seen 
pork meat or tasted it. Further, $90 \%$ of the participants reported that they would not eat pork or related foods under any circumstances, and $10 \%$ were curious about it and stated that they might eat it if they had to. Students were also asked why they did not eat pork meat within the scope of three main themes - religion, health and appearance - regarding the order of importance of their own preferences. The most important theme was religion; $80 \%$ of participants put it in the first place. They reported they did not eat pork as it was haram and was forbidden by Islam. This was followed by health: $57 \%$ of participants thought pork was unhealthy and put this option in the second place. Lastly, 30\% of participants reported that they did not eat pork since they were disgusted by the appearance of a pig as an animal. Additionally, two participants added that the prohibition of pork meat was a matter of social pressure. For the final question, learners were asked to match pork with an emotional expression. $75 \%$ of the participants matched "pork" with disgust emotion. $25 \%$ of the participants linked pork with fear, anger and "no emotion" option.

In sum, participants were unfamiliar with pork regarding both appearance and taste, they showed a negative attitude towards it due to religious restriction and had a potential of feeling disgust.

\section{Learner Reactions towards Pork: Facial Ex- pression Analysis Results}

This section aimed to present facial data results obtained while learners watched the recipe video. Mean values for 7 emotions and 3 valences were summarized below in Figure 2:

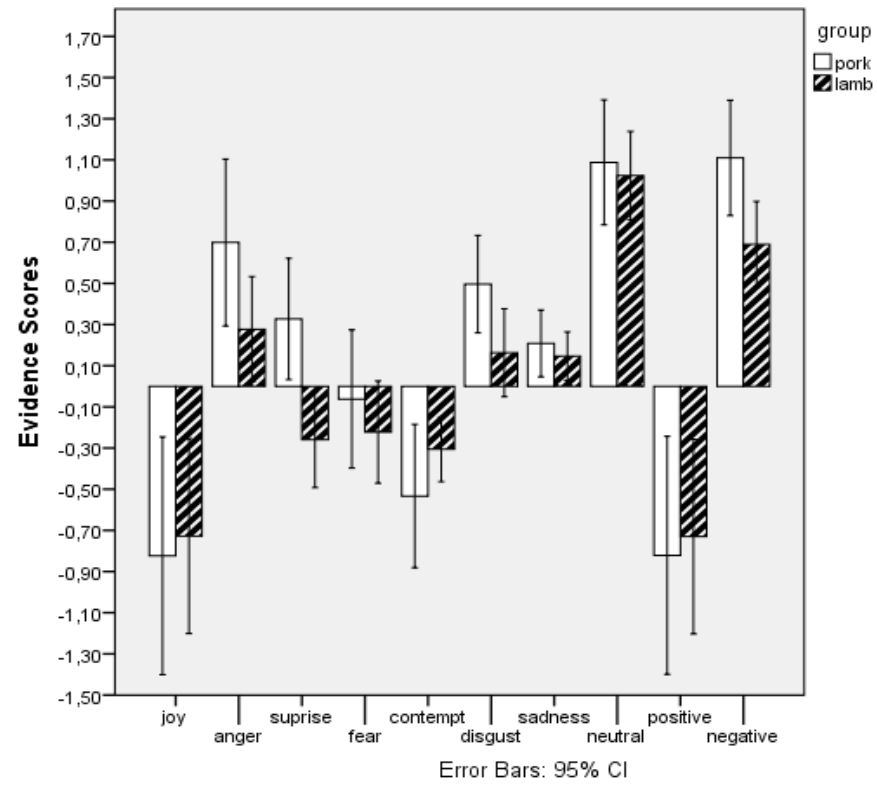

Figure 2 Evidence scores for each emotion and valence 


\section{Joy, Fear, Sadness and Contempt}

For joy, both groups scored under zero: the PG $(M=-.82, S D=1.23)$ and the $L G$ joy scores $(M=-.72, S D=1.01)$ were nearly similar. Members of both groups showed no joyful expression while watching the video. The results also showed that participants in both groups showed no expression of fear: The fear evidence for the PG $(M=-.06, S D=.71)$ was similar to that of the $\mathrm{LG}(M=-.22, S D=.53)$. Likewise, for contempt, the PG scores $(M=-.53, S D=.74)$ were nearly identical to the LG scores $(M=-.30, S D=.33)$. Finally, for sadness, the PG $(M=.20, S D=.34)$ and the $L G$ scores $(M=.15, S D=.25)$ were nearly equal. The evidence scores for the PG and LG were close for joy, sadness, fear and contempt and neither group exhibited a remarkable expression of these emotions.

\section{Anger, Disgust and Surprise}

For anger, the PG scores were higher $(M=.69$, $S D=.86)$ than those of the LG $(M=.27, S D=$

.54). Interestingly, the $P G$ seemed more surprised $(M=.32, S D=.62)$ than the $\operatorname{LG}(M=-.25, S D=$ $.45)$ while watching the video. Similarly, for disgust, the PG was more likely to show disgust $(M=.48, S D=.47)$ than the $\operatorname{LG}(M=.13, S D=$ $.45)$. In sum, PG was found to have slightly greater expression of anger, surprise and disgust than LG group did.

\section{Valence: Negative, Positive and Neutral}

For positive valence, the $\mathrm{PG}(M=-.82, S D=$ $1.23)$ and $\mathrm{LG}$ scores $(M=-.73, S D=1.01)$ were close, meaning that the groups were equally negative towards the video. Similarly, the neutral valence scores for PG $(M=1.08, S D=.64)$ and LG $(M=1.02, S D=.45)$ showed that both groups had nearly equal neutral expressions. Finally, negative evidence score of the PG $(M=$
$1.10, S D=.59)$ was higher than that of the $\mathrm{LG}$ $(M=.68, S D=.44)$.

Facial data results indicated a negative stance of learners towards pork content covering especially anger, surprise and disgust. Values for joy, fear, sadness and contempt were similar between groups.

\section{Learners' Attitudes versus Facial Expres- sions: The Case of Disgust Emotion}

This section aims to 1) build a link between disgust scale and biometric data results (facial data), 2) whether groups differ significantly in terms of disgust emotion. For this aim, $t$-test and Pearson correlation were used.

Disgust was chosen as the "criterion emotion" since a majority of learners matched "pork" with "disgust emotion" in the Pork Taboo Survey. Additionally, results of the disgust scale given after watching the video showed that learners found pork significantly more disgusting $(M=4.30, S D=1.89)$ than lamb meat, which was favored $(M=7.45, S D=1.39) ; t(38)=5.988$, $p=.000$. Moreover, $75 \%$ of the learners in the pork condition reported that they would not eat the dish, and $20 \%$ were indecisive. In the LG, $80 \%$ reported that they would eat the meal and $20 \%$ were indecisive.

In sum, preliminary findings revealed a disgust tendency towards pork and disgust scale results indicated that learners were disgusted by the pork content. Results of the facial expression data also confirmed these results: Pearson correlation results indicated a negative relationship between disgust scale results and disgust evidence scores; $r=-.388, n=40$, $p=.013$. Additionally, facial data results revealed a significant difference between groups in terms of disgust emotion expressed while watching the video; $t(38)=2.323, p=.026$. In this respect, facial expression analysis findings validated the subjective learner attitude towards pork: Learners in the pork condition were ob- 
served to have shown more disgust while watching the video, as they had stated in the disgust scale and pork taboo survey.

\section{The Effect of Pork Content on Learning Gains}

Learner opinions and facial data results consistently revealed that learners held a negative stance towards pork and they expressed disgust emotion while processing pork visuals in a multi modal language learning environment. Thus, the current research question was aimed to investigate any effect of this negative stance on vocabulary learning gains. The expectation was that learners' disgust of pork would have a negative impact on their vocabulary retention and post-test performance. Contrary to the predictions, learners who watched the pork content scored better in average $(M=11 ; S D=6.8)$ than the lamb meat group $(M=8.4 ; S D=6)$. Yet, this difference was not found to be significant; $t(38)=1.326 ; p=.193$. Post-test consisted of 3 main components; a stimulated recall procedure, a close test and a writing-words section; respectively. For each component, the maximum score was 12 . Mean scores for each group regarding 3 components were as follows:

According to Table 2, PG and LG scores were close and no statistically significant difference was found between their performances. Based on these findings, it can be proposed that pork content did not pose a threat to vocabulary learning gains.

\section{Discussion}

\section{Attitudes and Facial Reactions Towards Ta- boo Content}

Preliminary findings showed that Muslim learners were naive to pork due to their social milieu and would not consume it as part of their diet, mainly due to religious reasons. A majority of them also linked pork with the feeling of disgust. In this respect, Muslim learners kept their distance to pork and held a negative stance towards it. These findings confirmed some related research arguing that language learners do not relate well to taboo topics (Argungu, 1996; Deckert, 1996; Gobert, 2003; Hudson, 2011; Khuwaileh, 2000; Timina \& Butler, 2011). The learners' negative stance towards pork also paralleled facial data analysis results: Muslim learners were disgusted by the pork content while watching the recipe video for language learning purposes.

Muslim learners not only thought pork was disgusting but also felt disgusted while processing the pork content for learning purposes. These confirmatory findings have shown that taboos should be handled with care during language instruction. In addition, results also supported Gray (2002) and Akbari (2008), who

Table 2 Mean scores for Post-Test components

\begin{tabular}{llcccc}
\hline & Group & Mean Score & Std. Deviation & Std. Error Mean & Sig. \\
\hline \multirow{2}{*}{ Stimulated Recall** } & pork & 5.15 & 2.85 & .63 & \multirow{2}{*}{.386} \\
\cline { 2 - 6 } & lamb & 4.40 & 2.54 & .56 & \multirow{2}{*}{.62} \\
\hline \multirow{2}{*}{ Cloze Test* } & pork & 3.35 & 2.08 & .46 & .45 \\
\cline { 2 - 6 } Writing Words* & lamb & 2.10 & 2.02 & .62 & \multirow{2}{*}{.363} \\
\cline { 2 - 6 } & pork & 2.65 & 2.81 & .42 & \\
\hline
\end{tabular}

Note. *max score was 12 points 
warned about taboo topics in ELT with the acronym "PARSNIPS" (politics, alcohol, religion, sex, narcotics, -isms and pork). These results also verified Gobert's work (2015), who emphasized that teachers of English with a Muslim audience (especially in the Gulf Region) should be sensitive to the use of taboo topics, including pork, in their instructional content as there is no legal protection for them.

\section{Effect of Taboo Content on Incidental Vocabu- lary Learning Gains}

Facial expression analysis findings indicated that the pork content invoked more emotional arousal, mostly consisting of negative emotions; especially disgust. Regarding learning gains, learners exposed to taboo content did not perform any worse: Disgusting pork content seemed to have no negative effect on language learning gains and memory performance. Emotionally loaded stimuli are distinct (Talmi \& McGary, 2012) and remembered better than neutral stimuli (Cahill \& McGaugh, 1995). Research on the relation between memory and emotion has shown that memory mechanisms are positively affected by the intensity of emotion experienced, regardless of the direction of emotional valence (Nielson \& Powless, 2007; Talarico, LaBar, \& Rubin, 2004). In this respect, emotional salience caused by pork content caused no negative impact on remembering the target words. The results of this study were also consistent with a similar study by Finn and Roediger (2011), who examined the role of emotional priming on vocabulary retention among Swahili learners. Their findings revealed that Swahili learners remembered significantly more word pairs that were primed by negative emotional pictures than the word pairs primed by neutral stimuli or a blank screen. Different from their study, this study found no significant difference between groups.
Taboos do not necessarily lead to poor cognitive performance as emotional intensity provided by taboo content may support memory mechanisms. Hence, the offense caused by the pork content is not related to academic performance but it is solely an emotional state caused primarily by pork taboo determined by cultural norms.

\section{Conclusion}

This study explored how taboos might affect learner psychology and language learning processes by blending learner opinions, recall tests and facial expression analysis. The results showed that Muslim learners were sensitive towards the pork taboo and felt disgusted while processing pork content. One clear conclusion is that Muslim EFL learners not only kept their distance to the pork taboo but they also showed negative facial expressions. This conclusion is remarkable since it supports the recent cultural road map of some ELT publishers, who recently excluded pork content in their textbooks for Muslim learners (Flood, 2015; Harley, 2015). Secondarily, the results also provide an insight for language pedagogy in Islamic regions, postulating that inclusion of pork content in language instruction is more likely to cause discomfort among Muslim learners. The level of reactions may fluctuate depending on the depth of Islamic mentality. Thus, western instructors in such regions should handle pork with care.

Another conclusion to draw from this study is that taboos cause emotional reactions, which have no adverse effect on learner cognition. Hence, taboos can be criticized as being psychologically offensive for language learners, however, the current results showed no negative impact on language learning gains and academic performance.

It should be noted that the exclusion of pork topic in language learning contradicts Critical Pedagogy (Freire, 1973; Giroux, 1983) - a term 
that emphasizes going beyond arbitrary social constraints in classrooms and pursuing social transformation through education (Akbari, 2008). Censoring pork content in educational settings will surely divert learners to learn "pork" related vocabulary from informal contexts and thus the target culture instruction will be incomplete. Material designers, publishers and instructors should keep this in mind before hiding pork and papering it over the cracks.

Evans, Avery, and Pederson (1999) enlisted a vast range of taboo topics in education, such as abortion and religious restrictions, and stated that "These are issues that can generate great controversy, but they are generally perceived as public issues. They are also issues in the larger society, and several of them may be a step removed from students' lives." In educational settings taboo topics are controversial but avoiding them cannot take them out of students' lives. Indeed, taboos all exist in public life; for Muslim language learners, "pork" and related vocabulary will not disappear from Western culture when it is not taught as a part of language education.

Additionally, strictly avoiding taboo topics obstruct the acculturation process. In second language acquisition, "The Acculturation Model" is a theory created by John Schumann (1986) in order to explain the language acquisition process of immigrants, migrant workers, or the children of such groups (Ellis, 1994, p. 230). The primary argument of this theory is that the acquisition of a second language is directly dependent on the acculturation process and acquisition success is determined by the extent to which learners can orient themselves in the target language culture (VanPatten \& Benati, 2015). The problems in cultural orientation lead to severe culture shock, which may result in decreased success in learning the target language. In this regard, avoiding taboos involving pork content makes it harder for students to have a healthy cultural orientation when they go abroad or meet with new people from the target culture.

Finally, this study introduced facial expression analysis technique to the field. The findings were consistent and reasonable, showing that when applied correctly, facial expression analysis as a research technique can give inspiring clues on how language learners process visuals and linguistic input in different learning environments.

\section{Limitations and Further Recommendations}

The first limitation of this study was the possible priming effect of Pork Taboo Survey, which was conducted 1 week before the main experiment. Although 1 week is a relatively long time span, learners may have been slightly affected by the priming effect. Secondly, learners found recall tests slightly challenging and thus scored low causing a floor effect. Indeed, words to be remembered were short and recall tasks were done right after the experiment; however, this still stands as a limitation.

Computer assisted facial expression analysis is developing thanks to the rapid growth of software technologies. In this respect, this technique can find an application among researchers in various fields of research. For second language learning and development, a further study may cover facial expressions of learners in language classroom context and its relation to academic performance. With the use of the right equipment, facial expressions of crowds can be analyzed moment by moment, which enables the analysis of several students in language classrooms at the same time.

\section{References}

Alptekin, C. (1993). Target-language culture in EFL materials. ELT journal, 47(2), 136-143. https:// doi.org/10.1093/elt/47.2.136

Akbari, R. (2008). Transforming lives: Introducing critical pedagogy into ELT classrooms. ELT jour- 
nal, 62(3), 276-283. https://doi.org/10.1093/elt/ $\operatorname{ccn} 025$

Argungu, D. M. (1996). English Muslims and islamisation: Between needs and deeds. English and Islam: Creative Encounters, 96(3), 331-347.

Banegas, D. L. (2011). Teaching more than English in Secondary Education. ELT Journal, 65(1), 80-82. https://doi.org/10.1093/elt/ccq016

Buck, R. (1984). The communication of emotion. New York: Guilford Press.

Cahill, L., \& McGaugh, J. L. (1995). A novel demonstration of enhanced memory associated with emotional arousal. Consciousness and Cognition, 4, 410-421. https://doi.org/10.1006/ccog.1995. 1048

Calvo, M. G., Gutiérrez-García, A., \& Del Líbano, M. (2016). What makes a smiling face look happy? Visual saliency, distinctiveness, and affect. Psychological Research, 82(2), 296-309. https://doi.org/ 10.1007/s00426-016-0829-3

D’Mello, S. K. (2016). Automated mental state detection for mental health care. In D. Luxton (Ed.), Artificial Intelligence in Behavioral and Mental Health Care (pp. 117-131). Elsevier/Academic Press: San Diego, CA. https://doi.org/10.1016/B9780-12-420248-1.00005-2

Danner, L., Sidorkina, L., Joechl, M., \& Duerrschmid, K. (2014). Make a face! Implicit and explicit measurement of facial expressions elicited by orange juices using face reading technology. Food Quality and Preference, 32, 167-172. https://doi.org/ 10.1016/j.foodqual.2013.01.004

Deckert, G. (1996). Ethical considerations in addressing values in the ESL classroom. In Annual Meeting of the Teachers of English to Speakers of Other Languages. Chicago, IL.

Ekman, P. (1982). Emotion in the Human Face. CUP

Ekman, P., \& Friesen, W. V. (1971). Constants across cultures in the face and emotion. Journal of Personality and Social Psychology, 17(2), 124-129. https:/ /psycnet.apa.org/doi/10.1037/h0030377

Ekman, P., \& Friesen, W. (1978). Facial action coding system. Consulting Psychologists Press Inc., Palo Alto, California.

Ellis, R. (1994). The study of second language acquisition. Oxford: Oxford University Press.

Encyclopædia Britannica Online. "Taboo." Encyclopædia Britannica Inc., 2012. Retrieved 3 November 2018 from https://www.britannica.com/topic/taboosociology.

Essa, I. A., \& Pentland, A. P. (1997). Coding, analysis, interpretation, and recognition of facial expressions. IEEE Transactions on Pattern Analysis and Machine Intelligence, 19(7), 757-763. https://doi.org/ $10.1109 / 34.598232$
Evans, R. W., Avery, P. G., \& Pederson, P. V. (1999) Taboo topics: Cultural restraint on teaching social issues. The Social Studies, 90(5), 218-224. https:// doi.org/10.1080/00098650009600973

FACET FAQ retrieved from https://help.imotions.com/ hc/en-us/articles/205256321-FACET-FAQ in 12.10 .2017

Fasel, B., \& Luettin, J. (2003). Automatic facial expression analysis: A survey. Pattern Recognition, 36(1), 259-275. https://doi.org/10.1016/S00313203(02)00052-3

Finn, B., \& Roediger, H. L. (2011). Enhancing retention through reconsolidation: Negative emotional arousal following retrieval enhances later recall. Psychological Science, 22(6), 781-786. https://doi.org/ 10.1177\%2F0956797611407932

Flood, A. (2015). Pigs won't fly in textbooks: OUP tells authors not to mention pork. The Guardian. Retrieved from https://www.theguardian.com/books/ $2015 /$ jan/14/pigs-textbooks-oup-authors-porkguidelines

Flynn, K. (2014). Fostering critical thinking skills in students with learning disabilities through online problem-based learning. International Association for Development of the Information Society.

Freire, P. (1973). Education for critical consciousness (Vol. 1). Bloomsbury Publishing.

Fridlund, A. J., Ekman, P., \& Oster, H. (1987). Facial expressions of emotion: Review of the literature, 1970-1983. In A. W. Siegman \& S. Feldstein (Eds.), Nonverbal behavior and communication (pp. 143224). Hillsdale, NJ: Erlbaum.

GhasemAghaei, R., Arya, A., \& Biddle, R. (2016). A dashboard for affective E-learning: Data visualization for monitoring online learner emotions. In Proceedings of EdMedia: World Conference on Educational Media and Technology. Vancouver, Ca.(28 Jun 2016).

Giroux, H. (1983). Theory and resistance in education: A pedagogy for the opposition. South Hadley, MA: Bergin \& Garvey.

Gobert, M. (2003). Avoiding cultural confrontation in the classroom: An analysis of four mainstream integrated ESL textbooks. In S. Zafar (Ed.), Culture, context and communication in English language teaching. Proceedings of the 3rd annual teacher to teacher Conference (pp. 220-233). Abu Dhabi: Military Language Institute.

Gobert, M. (2015). Taboo topics in the ESL/EFL classroom in the Gulf region. In intercultural communication with Arabs (pp. 109-126). Springer Singapore. https://doi.org/10.1007/978-981-287254-8 7

Gray J. (2002). The global coursebook in English language teaching. In D. Block \& D. Cameron (Eds.), 
Globalization and language teaching (pp. 151167). London, England: Routledge.

Harley, J. (2015). No, we haven't banned books on pigs - but sensitivity is key in global publishing. The Guardian. Retrieved from https://www.theguardian. com/commentisfree/2015/jan/15/books-pigs-globalpublishing-oxford-university-press-children

Hudson, P. (2011). Beef and Lamb, Chicken and $\mathrm{H}^{* *}$ censorship and vocabulary teaching in Arabia. $H C T$ Maarifa, 125-135.

Khuwaileh, A. A. (2000). Cultural barriers of language teaching: A case study of classroom cultural obstacles. Computer Assisted Language Learning, 13(3), 281290. https://doi.org/10.1076/0958-8221(200007) $13: 3 ; 1-3 ;$ FT281

Kling, A. S., \& Brothers, L. A. (1992). The amygdala and social behavior. In J. P. Aggleton (Ed.), The amygdala: Neurobiological aspects of emotion, memory, and mental dysfunction (pp. 353-377). New York, NY, US: Wiley-Liss.

LeDoux, J. E. (1993). Emotional memory systems in the brain. Behavioural Brain Research, 58(1), 69-79. https://doi.org/10.1016/0166-4328(93)90091-4

Nazari, Z., Lucas, G., \& Gratch, J. (2015). Multimodal approach for automatic recognition of Machiavellianism. In proceedings of the 2015 International Conference on Affective Computing and Intelligent Interaction (ACII) (pp. 215-221). IEEE. https:// doi.org/10.1109/ACII.2015.7344574

Nelson, C. (1999). Sexual identities in ESL: Queer theory and classroom inquiry. TESOL Quarterly, 33(3), 371391. https://doi.org/10.2307/3587670

Neto, J. C., \& Filipe, J. A. (2016). Consumers economic behavior and emotions: The case of iphone 6 in neuromarketing. International Journal of Latest Trends in Finance and Economic Sciences, 5(4), 1041-1047.

Neubauer, C., Woolley, J., Khooshabeh, P., \& Scherer, S. (2016). Getting to know you: A multimodal investigation of team behavior and resilience to stress. In Proceedings of the 18th ACM International Conference on Multimodal Interaction (pp. 193-200). ACM.

Nielson, K. A., Powless, M. (2007). Positive and negative sources of emotional arousal enhance long-term word-list retention when induced as long as $30 \mathrm{~min}$ after learning. Neurobiology of Learning and Memory, 88(1), 40-47. https://doi.org/10.1016/ j.nlm.2007.03.005

Pellegrino, R., Crandall, P. G., \& Seo, H. S. (2015). Hand washing and disgust response to handling different food stimuli between two different cultures. Food Research International, 76, 301-308. https: //doi.org/10.1016/j.foodres.2014.12.027

Picard, R. W. (1995). Affective computing. M.I.T Media Laboratory Perceptual Computing Section Technical Report No. 321.

Rastle, K., Harrington, J., \& Coltheart, M. (2002). 358,534 nonwords: The ARC nonword database. Quarterly Journal of Experimental Psychology, 55A, 1339-1362. doi: 10.1080/02724980244000099

Schumann, J. H. (1986). Research on the acculturation model for second language acquisition. Journal of Multilingual \& Multicultural Development, 7(5), 379-392. https://doi.org/10.1080/01434632.1986. 9994254

Smith, E. E., \& Kosslyn, S. M. (2013). Cognitive psychology: Pearson new international edition: Mind and brain. Pearson Higher Ed.

Talarico, J. M., LaBar, K. S., \& Rubin, D. C. (2004). Emotional intensity predicts autobiographical memory experience. Memory \& Cognition, 32(7), 1118-1132. https://doi.org/10.3758/BF03196886

Talmi, D., \& McGarry, L. M. (2012). Accounting for immediate emotional memory enhancement. Journal of Memory and Language, 66(1), 93-108. https:/ /doi.org/10.1016/j.jml.2011.07.009

Tekin, M. (2011). Discussing the unspeakable: A study on the use of taboo topics in EFL speaking classes. Journal of Theory and Practice in Education, 7(1), 79-110.

Timina, S. A., \& Butler, N. L. (2011). Uncomfortable topics and their appropriateness in Asian EFL classes. Retrieved from ERIC Database (ED515120).

Üstünel, E., \& Öztürk, S. (2014). The impact of culturally enriched classes on young learners. ELT Research Journal, 3(4), 222-244.

VanPatten, B., \& Benati, A. G. (2015). Key terms in second language acquisition. Bloomsbury Publishing. 